\title{
Ciencia, animal y fantasma en La comemadre e Informe sobre ectoplasma animal de Roque Larraquy*
}

\author{
Science, animal and ghost in Roque Larraquy's \\ La comemadre and Informe sobre ectoplasma animal
}

\author{
VALERIA DE LOS RÍOS \\ Instituto de Estética. Pontificia Universidad Católica de Chile \\ Correo electrónico: edelo@uc.cl
}

En sus dos novelas La comemadre (2010) e Informe sobre ectoplasma animal (2014) Roque Larraquy trabaja en los límites del discurso científico-positivista que se empieza a configurar en los comienzos del siglo XX en Argentina. En ambos trabajos, la ciencia funciona como sinécdoque de la modernidad y se presenta como un complejo ensamblaje en el que se cruzan pseudociencias y experimentaciones con cuerpos de animales humanos y no humanos. En La comemadre los animales no humanos aparecen como cuerpos disponibles para la experimentación, que poco a poco son reemplazados por cuerpos de animales humanos, compartiendo así su estatus de disponibilidad para la indagación científica. El carácter fantasmal de los animales, es explorado intensamente en Informe sobre ectoplasma animal. Allí el animal como recurso se convierte literalmente en un espectro, que no se cansa de reaparecer, amenazando e interrumpiendo el presente.

Palabras clave: literatura argentina, ciencia, biopolítica, animalidad

In his two novels, La comemadre (2010) and Informe sobre ectoplasma animal (2014), Roque Larraquy works in the limits of the scientific-positivist discourse that begins to take shape in early 20th century Argentina. In both books, science operates as a synecdoche of modernity, and presents itself as a complex assembly in which pseudosciences and experiments with human and non-human animal bodies intersect. In La comemadre, nonhuman animals appear as bodies available for experimentation, which are gradually replaced by human bodies, thus sharing their availability for scientific research. The ghostly character of animals is explored intensely in Informe sobre ectoplasma animal. There the animal as a resource literally becomes a spectrum, which constantly reappears, threatening and interrupting the present.

Key words: Argentine literature, science, biopolitics, animality

Este artículo forma parte del proyecto FONDECYT No 1130363 (CONICYT, Chile) "Vida y animalidad en la literatura latinoamericana”, Universidad Finis Terrae y Pontificia Universidad Católica de Chile (2013-2016). 
En sus dos novelas La comemadre (2010) e Informe sobre ectoplasma animal (2014) Roque Larraquy trabaja en los límites del discurso científico-positivista que se empieza a configurar en los comienzos del siglo XX en Argentina. En ambos trabajos, la ciencia funciona como sinécdoque de la modernidad y se presenta como un complejo ensamblaje en el que se cruzan pseudociencias y experimentaciones con cuerpos de animales humanos y no humanos, dando cuenta de ordenamientos que, como dice Gabriel Giorgi siguiendo la impronta de Michel Foucault, "definen jerarquías entre cuerpos y entre formas de vida", ya que "lo humano se constituye políticamente a partir de una gestión de los cuerpos" (2014: 41).

En La comemadre, los animales no humanos aparecen como cuerpos disponibles para la experimentación que, poco a poco, son reemplazados por cuerpos humanos, compartiendo e igualando así su estatus de disponibilidad para la indagación científica en un contexto de establecimiento de la economía capitalista, en la que Argentina se insertaba como exportadora de productos primarios de origen agropecuario. Informe sobre ectoplasma animal cubre sin linealidad histórica el periodo que va desde 1911 a 1957. En esta novela se explora el carácter fantasmal de los animales, ya que allí el cuerpo del animal no humano como recurso se convierte literalmente en un espectro, que no se cansa de reaparecer, amenazando e interrumpiendo el presente. Paralelamente, el discurso estético y el campo del arte aparecen como espacios en los que opera, como en la ciencia, la experimentación, en los que técnicas de registro o de creación permiten visibilizar formas nuevas a partir de cuerpos. Del mismo modo, la imaginación literaria se alimenta de estas ficciones científicas que cuestionan y llevan al límite las nociones de racionalidad y experimentación artística.

Esta conjunción entre narrativa y ciencia, en Argentina no es nueva. Existen numerosos ejemplos que marcan esta vinculación de modos diversos, mezclando las narrativas con información científica para generar verosimilitud. En algunos casos, estas tendencias aparecen combinadas con conocimientos espiritualistas que tensionan las tendencias más racionalistas y crean el suspenso. Dentro de esta corriente se cuentan autores como Eduardo Ladislao Holmberg, Leopoldo Lugones y Horacio Quiroga ${ }^{1}$. A diferencia de lo que ocurre con estos escritores, en los que la racionalidad muestra sus flaquezas y sus limitaciones, las narrativas de Larraquy muestran un racionalismo descarnado que, a la inversa de lo que ocurría con los escritores de esta tradición argentina, demuestran que la espiritualidad o la trascendencia es sólo una excusa para la ciencia y que la experimentación puede convertirse en una más de las formas de practicar un arte mercantilizado y polemizante. Si se imagina que la vida existe más allá de la muerte o si se comprueba que en los seres vivientes hay algo que se niega a desaparecer, más que sembrar la sospecha sobre la posibilidad de una trascendencia (como lo hacían las narrativas de fines del siglo XIX y principios del XX antes mencionadas), las narrativas de Larraquy se centran en la posibilidad de ganancia económica, fama o reconocimiento institucional, aunque estos jamás lleguen. En ese sentido, el trabajo

\footnotetext{
$1 \quad$ Para estudios centrados en la obra de Holmberg, revisar los trabajos de Sandra Gasparini y Claudia Román. Sobre las relaciones entre ciencia y espiritismo en Argentina, ver el libro de Soledad Quereilhac (2016).
} 
de Larraquy está más emparentado con el de Roberto $\operatorname{Arlt}^{2}$, para quien la fabulación técnica, incluso mezclada con tendencias espiritualistas, marca de algún modo el deseo de entrar en el mercado o el capitalismo industrializado, o multinacional, dependiendo del contexto histórico en que inscriba su ficción.

\section{LA COMEMADRE: EL CUERPO DEL DELITO Y EL BIOARTE}

Dividida en dos partes - una situada en un sanatorio en las cercanías de Buenos Aires en 1907 y la otra en el Buenos Aires del 2009- La comemadre (2010) relata dos momentos de la historia y cultura Argentina: primero el auge del positivismo científico ${ }^{3}$ en un sanatorio, donde un experimento con la guillotina en seres vivientes (primero un pato) da cuenta de que la cabeza permanece "viva" por nueve segundos, lo que según un citado tratado sobre el tema contradice la idea de castigo y convierte al público en espectáculo. El jefe de los médicos, el Dr. Ledesma, lee un informe en el que relata el impacto de la guillotina

La genealogía de los textos de Larraquy, emparentada con la escritura de Roberto Arlt, se hace evidente
cuando revisamos algunos textos críticos sobre la obra de Arlt. En La imaginación técnica Beatriz Sarlo escribe:
"La pregunta acerca del orden social, que recorre Los siete locos y Los lanzallamas, tiene una respuesta técnica y
otra mítica. En las novelas de Arlt ambas dimensiones están unidas: la técnica hace posible, aliada a la riqueza,
la producción tanto de un orden como de una mitología, a condición de que sea manejada por un cuerpo de
expertos, verdaderos revolucionarios decididos a todo, que construyan con los recursos de la técnica las bases
de un nuevo poder político. El industrialismo no es sólo un deseo bolchevique ni sólo el motor del capitalismo
occidental o el militarismo expansionista, sino también una de las formas literarias de esta ensonación moderna:
el 'misticismo industrial' se apoya en una transmisión estética de la ciencia, con cuyos recursos se dispone de un
parnaso de 'dioses supercivilizados" (1997: 56). En una entrevista que dio en 1984, y publicada en Crítica y
ficción, Ricardo Piglia señala: "Para los personajes de Arlt no se trata de ganar dinero, sino de hacerlo. Esta tarea
asociada con la falsificación y la estafa, pero también con la magia, las artes teosóficas y la alquimia, se afirma
en la ilusión de transformar la miseria en dinero. En Los siete locos, Erdosain trabaja de un modo casi religioso
para crear dinero de la nada. Sus inventos son una forma sublimada, alquímica, del beneficio capitalista" (2000:
26). Más que un vínculo estilístico entre Arlt y Larraquy, se trata de una imaginación común, que une ciencia,
técnica, políica, arte y magia, como discursos fundadores de la modernidad, y en cuya parodia o fracaso se
encuentran las claves paras entender el mundo contemporáneo.

3 En su entrada a "Positivism in Latin America" en The Encyclopedia of Postcolonial Studies, Paola CortésRocca afirma que para el Positivismo el conocimiento, que sigue la forma de las ciencias naturales, consiste en identificar leyes sobre un fenómeno dado y hacer coincidir el objeto de estudio con lo observable. Esta actitud metodológica estaría además determinada históricamente a través de una línea progresiva, constituyéndose simultáneamente en un programa y en una descripción de un campo metodológico de fin de siglo. Siguiendo a Oscar Terán, Cortés-Rocca asegura que en el contexto latinoamericano el positivismo se convierte en una "matriz mental" dominante entre 1880 y 1910: "este lugar hegemónico responde, por un lado a su capacidad de funcionar como relato clave para la interpretación nacional y por otro, a su capacidad de articularse con instituciones específicas en el área educativa, jurídica, sanitaria y militar, lo que la define como una verdadera práctica discursiva, en el sentido que Michel Foucault le da al término: un dispositivo que articula discursos, instituciones, saberes y prácticas." (2016b: s/n) 
como método de castigo técnica. La figura del verdugo se reduce a su minima expresión, la del operario de una máquina. La estricta funcionalidad del nuevo método no deja lugar para el estilo" (21). Considerada de esta forma, la ejecución por guillotinamiento deja de ser un arte y se convierte en una técnica que se pone al servicio del progreso científico. El afán de experimentación y el deseo por conocer lo que esas cabezas pueden "ver" una vez separadas de su cuerpo, lleva a los médicos del establecimiento, financiados por un inmigrante inglés, a publicitar en la revista Caras y caretas un anuncio que promete la cura contra el cáncer, con la idea de obtener pacientes terminales para el experimento. El aviso, señala lo siguiente:

Buenos Aires. 20 de julio de 1907. Sanatorio Temperley. Establecimiento especial para el tratado del Cáncer y Enfermedades de la Sangre. Es evidente que el cáncer se cura por completo con el suero anticanceroso del Profesor Beard, de la Universidad de Edimburgo (Inglaterra.) El suerto anticanceroso se aplica en los hospitales principales de Europa, los Estados Unidos y el Sanatorio Temperley con sorprendentes resultados. El Sanatorio Temperley es el unico establecimiento autorizado por el Doctor Beard para la aplicación de este tratamiento en la República Argentina. Las consultas son gratuitas de 10 a 12 a.m. y deben dirigirse al "Sanatorio Temperley", Temperley F.C.S. En la capital pueden obtenerse informes en Bolivar 332, de 1 a 3 p.m. (28).

Este aviso tiene un referente real que no es incluido como tal al interior de la novela. Roque Larraquy cuenta que le gustan las cosas viejas y poseía el ejemplar de Caras y Caretas donde aparece el aviso que da origen al libro.

\footnotetext{
$4 \quad$ En la primera parte de la novela todos los textos que no corresponden a la escritura del diario por parte del Dr. Quintana están escritos en cursiva.
} 


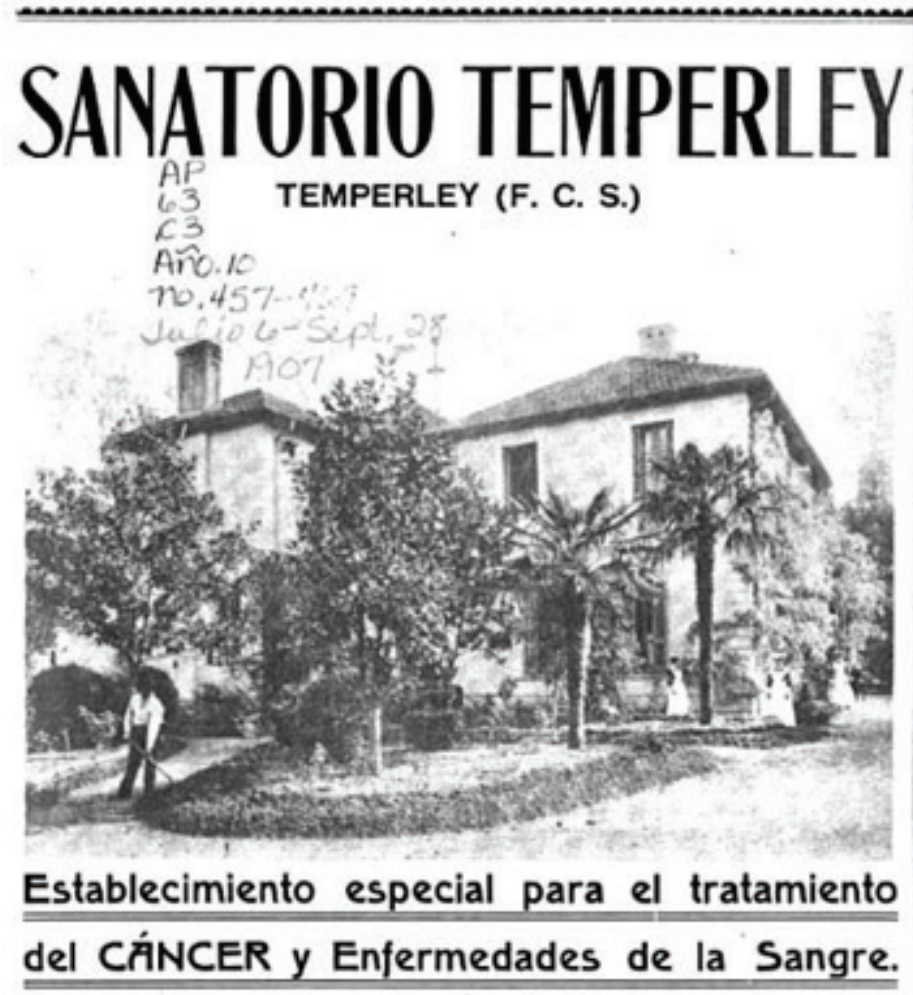

Es evidente que el CÁNCER se cura por completo con el Suero Anti-Canceroso del Profesor Beard, de la Universidad de Edimburgo (Inglaterra).

El Suero Anti-Canceroso se aplica en los Hospitales principales de Europa, los Estados Unidos y el "Sanatorio Temperley" con sorprendentes resultados.

El "Sanatorio Temperley" es el ûnico establecimiento autorizado por el Doctor Beard para la aplicación de este tratamiento en la República Argentina.

Las consultas son gratuitas de 10 a 12 a. m. y deben dirigirse al "Sanatorio Temperley", Temperley F. C. S.

En la capital pueden obtenerse informes en Bolivar, 332, de 1 a 3 p. m. 
El registro de la experiencia es realizado por el doctor Quintana, quien anota en su diario un registro de la vida en el sanatorio y los oscuros personajes que lo habitan. El diario describe, por ejemplo, las perversiones del Dr. Papini y su obsesión por la antropometría 5 , el amor imposible del dueño del sanatorio por Menéndez, la jefa de las enfermeras, de quien el Dr. Quintana también está enamorado, o el suicidio del Dr. Sisman, involucrado sentimentalmente con una paciente que sufre de alucinaciones. Sisman, antes de morir, le regala a Quintana una colección de ranas metálicas sonoras, creadas con el objetivo de entretener a niños ciegos. Estas ranas, que luego heredará un nieto del doctor Quintana, serán el puente que unirá ambas partes de la novela. Quintana se convierte así en el testigo privilegiado de lo que ocurre en el sanatorio y es él, al mismo tiempo, quien inscribe el registro de los acontecimientos en un texto confuso, mitad diario personal, mitad registro objetivo del experimento, en el que se reproducen informes, datos y conversaciones con los distintos personajes involucrados, pero también pensamientos, deseos y dudas que van apareciendo a lo largo del tiempo que dura el experimento, el cual termina de manera trágica.

En la sección situada en 1907 abundan las alusiones animales: las hormigas que observa diaria e insistentemente el Dr. Quintana, las moscas que la paciente alucina, el pato guillotinado y los simios a los que alude el Dr. Papini como antecedentes de los homínidos atávicos que persigue con su pinza antropométrica. Papini confía en el poder de clasificación de todas las criaturas a partir de la medición de su cráneo, por ello le comenta al doctor Quintana:

Las mujeres se maquillan para borrarse la cara, se ajustan en un corsé, y tienen muchos orgasmos, ¿sabe?, una cantidad que a nosotros nos dejaría secos. Son distintas. Salieron de un mono especial, que antes era una nutria, que antes fue un anfibio azulado, o algo con branquias. La forma de la cabeza la tienen distinta, también. Se encierran a usar el bidet para pensar cosas mojadas que se adaptan a las líneas de su cráneo. La amenaza. Yo soy un hombre bueno, no tengo alma para impedir la amenaza. Pero hay otros que sí. Las toman de los pelos y les preguntan el porqué de tanto tiempo perdido en el bidet. Y si la mujer no habla, la cosen a cuchilladas. Esos hombres son tan distintos de nosotros como ellas. Salieron de un mono distinto, de una escala inferior al nuestro, pero saludable y persistente (14-15).

Tanto las mujeres como los hombres parecen ubicarse en una escala jerárquica en la que los hombres con educación, como el propio Papini y Quintana, ocupan un lugar privilegiado. Sin embargo, para Papini, quien sigue fehacientemente las consecuencias de la teorías de la evolución planteadas por Charles Darwin ${ }^{6}$, resulta innegable que todos los

\footnotetext{
5 Ciencia que estudia las medidas del cuerpo humano con el fin de establecer diferencias entre razas, individuos o grupos. Tiene su origen en el siglo XVIII, aunque se considera su descubrimiento y estructuración científica definitiva en 1870, fecha en que se publica Anthropométrie del matemático belga Adolphe Quételet.

6 On the Origins of Species by Means of Natural Selection fue publicado en 1859 y tuvo un gran impacto en Argentina. Gioconda Marún ha señalado que algunos de los datos publicados en ese libro habían sido
} 
seres humanos provienen de un tipo específico de mono. Esta contigüidad jerárquica entre hombres y animales tiene el correlato racista del dueńo del sanatorio por un lado y los espúreos logros del nacionalismo argentino a partir de las masas iletradas que donan su cuerpo a la ciencia, por el otro. El dueño del sanatorio, Mr. Allomby, asegura que el exterminio de los indígenas en la Argentina mejoró la dentición de las generaciones futuras, temperó el olor a axilas, mejoró la calidad de los burdeles y permitió el surgimiento de la industria de las máquinas de afeitar (27). Respecto al nacionalismo, Quintana anota en su diario que la mayoría de los donantes "se deja convencer porque intuye un desafío científico argentino de dimensión mundial, y en esa efusión de patriotismo entregan el cuerpo. El clima de gesta favorece el sí fácil" (63). Estos cuerpos legados a la ciencia carecen de educación, ya que se introduce un error de atribución en el anuncio en Caras y Caretas: se dice que Edimburgo está en Inglaterra, cuando en realidad está en Escocia, para evitar así la llegada de gente culta o muy escrupulosa. Con esto, los cuerpos de sujetos de clases menos privilegiadas, que ven el anuncio publicado con retraso (el narrador dice que la visión de las empleadas domésticas tiene siempre una semana de atraso), son inscritos en una temporalidad otra, marcada por las diferencias de clase, y son igualados a los cuerpos animales, siempre disponibles, compartiendo con ellos la condición de volverse útiles post mortem (43). Uno de los médicos del sanatorio, el doctor Gurian lee un instructivo en el que se seńala el procedimiento:

El cuerpo puede medirse en grados de utilidad. Buen útero, próspera descendencia. Brazos fuertes, tareas viriles. Dedos dúctiles, piano. La salud es condición excluyente para que el cuerpo se incorpore con éxito a las tareas del mundo. La enfermedad devalúa. ¿Cómo restituir dignidad a un enfermo terminal? Volviendo su cuerpo al campo de lo útil, post mortem (43).

La corporalidad aparece considerada aquí en su condición de vida natural o $z o e^{7}$, noción que excluye a la enfermedad, en la que las potencialidades físicas se encuentran devaluadas. Así, el cuerpo aparece como productivo o útil sólo cuando no está enfermo, de modo que la enfermedad se cristaliza como forma de exclusión de lo normativo. Puestos en esta nueva perspectiva, el experimento del sanatorio Temperley entra en el terreno de la tanatopolítica (el poder de hacer morir y dejar morir), que se alía, tal como lo señalaba Foucault ${ }^{8}$, a un principio económico: el cuerpo se vuelve productivo cuando está muerto,

obtenidos en Argentina durante el viaje que Darwin realizó a bordo del "Beagle". Este hecho llevó a proclamar a Domingo Faustino Sarmiento en un arranque de nacionalismo que el Darwinismo era, en efecto, argentino (Marún 1995).

Según Giorgio Agamben, en el mundo griego existen dos nociones para definir la vida: zố, que expresa el simple hecho de vivir, común a los seres humanos, los animales y los dioses; y bios, que designa la forma de vivir propia de un individuo o un grupo, la vida calificada, que para los griegos es la vida política (1995: 9).

$8 \quad$ En Historia de la sexualidad Michel Foucault afirma que la biopolítica corresponde a la organización del poder en torno a la vida (169), caracterizándose por la "administración de los cuerpos y la gestión calculadora 
o al menos, lo hace en el experimento durante los nueve segundos en los que pasa de la vida a la muerte.

Los médicos del sanatorio compiten para lograr la mayor cantidad de donantes, estimulados por un beneficio económico. Los experimentos se realizan sin datos concluyentes y el problema de qué hacer con los cuerpos -literalmente los restos de esa negociación entre vida, enfermedad, muerte y experimentación médica- se soluciona a partir de la comemadre que da título a la novela: una planta que contiene larvas animales microscópicas que la devoran y que son capaces de hacer desaparecer en poco tiempo a los cadáveres.

La segunda sección de la novela, situada en el 2009, es el registro testimonial de un artista visual contemporáneo que revisa su vida y obra a partir de la lectura de una tesis doctoral. De niño, el narrador-artista guardaba mascotas en una cajón de su escritorio: un hámster que le compraron a los seis años conservado en formol, una tortuga seca y dos periquitos vivos. A esta colección se suman las ranas metálicas que recibió de regalo de parte de un amante, quien es nieto del doctor Quintana. La obra plástica de este artista está vinculada con la corporalidad: su primera instalación incluye a un padre y a su hijo con dos cabezas y otra instalación, realizada en colaboración, utiliza manos reales robadas de la morgue. La obra hace alusión a las manos de Perón y al cadáver de Eva. Nacionalismo, positivismo y experimentación pasan desde la práctica de la medicina en el sanatorio Temperley, a principios del siglo XX, al campo del arte a fines de la primera década del siglo XXI. El descendiente del Dr. Quintana ha guardado el diario de su abuelo y los frascos con la ya extinta comemadre. El narrador anónimo describe una video performance que incluye cirugías plásticas y la acción de la comemadre sobre la pierna de un hombre en movimiento. La explicación que arguye para realizar ese trabajo también contiene elementos nacionalistas, aunque en ella se incorporan también elementos culturales periféricos y postdictatoriales:

Vamos a hacerlo porque tenemos con qué, y porque se nos ocurrió primero. Nuestro motivo de orgullo, nuestra vanidad. Algunos teóricos (...) dan por supuesto que la obra tiene padres en la dictadura, en las mutilaciones del cuerpo de Eva y, otra vez y hasta la náusea, en El matadero, de Echeverría (140).

Si bien en la primera parte de la novela el exterminio en la guillotina de enfermos de clase trabajadora se hace en nombre de la ciencia, en la segunda parte se utiliza la comemadre y partes corporales cercenadas en nombre del arte o más precisamente de lo que hoy se conoce como bioarte, práctica que fusiona arte, biología y tecnología en un contexto

de la vida" (1998: 170). "Ese bio-poder fue, a no dudarlo, un elemento indispensable en el desarrollo del capitalismo; éste no pudo afirmarse sino al precio de la inserción controlada de los cuerpos en el aparato de producción y mediante un ajuste de los fenómenos de población a los procesos económicos. [...E]l ajuste entre la acumulación de los hombres y la del capital, la articulación entre el crecimiento de los grupos humanos y la expansión de las fuerzas productivas y la repartición diferencial de la ganancia, en parte fueron posibles gracias al ejercicio del biopoder en sus formas y procedimientos múltiples. La invasión del cuerpo viviente, su valorización y la gestión distributiva de sus fuerzas fueron en ese momento indispensables." (1998: 171-172). 
de grandes transformaciones políticas, económicas y sociales, de las emergen también cuestionamientos éticos que involucran la preocupación por la vida y la crítica a la noción del arte como mercancía. En la primera parte de la novela el guillotinado pato es llamado "pato cartesiano" aludiendo a la experimentación como práctica metódica y racional con orígenes en el pensamiento filosófico-científico de René Descartes. En la segunda parte, en cambio, la video-performance incluida se titula "pathos cartesiano", apelando como chiste interno a la retórica que utiliza los sentimientos y el sufrimiento humano para afectar a un público determinado. Lo que comparten las distintas epistemes que incluye la novela (la de la ciencia experimental de principios del siglo XX y la del arte contemporáneo de principios del siglo XXI) es su vínculo ineludible con las materialidades corporales que necesitan como insumo para sus respectivas prácticas: ¿qué diferencia hay entre el experimento en el sanatorio y una instalación artística? Ambas prácticas comparten la instrumentalización y reificación de los cuerpos, ya sea de animales o de humanos, que son la materia prima para la experimentación, de modo que señalan el cuerpo viviente y en definitiva el binomio inseparable vida-muerte como el centro de sus preocupaciones. La comemadre -ese híbrido entre vegetal y animal-, que da título a la novela, es la única capaz de hacer desaparecer esa materialidad corpórea que borra las huellas del exterminio en nombre de la ciencia y la que desmaterializa la obra de arte, la vuelve efímera y literalmente descorporeizada.

\section{FANTASMAS ANimales}

En su segunda novela, Informe sobre ectoplasma animal (2014), realizada junto al diseñador gráfico Diego Ontivero, Larraquy hace reaparecer esa corporalidad material, pero en forma de ectoplasma. Informe sobre ectoplasma animal está contagiado por el lenguaje positivista que, primero, Severo Solpe, el ectografista pionero y ex fotógrafo social, sus ayudantes Martín Rubens y Julio Heiss, y luego el contagiado narrador, vierten con economía descriptiva, casi legal, en el relato de los casos. La intención es la de inscribir, como en una placa de cesio, los antecedentes que certifican estas presencias imperceptibles al ojo humano, pero que sin embargo afectan corporal y materialmente a los sujetos.

Según Gabriel Giorgi, las décadas que cubre el libro son las décadas donde se juega la saga del Estado militarizado en Argentina: el primer golpe de Estado de 1930, y el que derroca a Perón en 1955. En ese ciclo empiezan a aparecer espectros animales que interrumpen la vida cotidiana y el funcionamiento de la ciudad. Giorgi escribe:

Ningún cuerpo desaparece, nunca, del todo: sus materias retornan, en su propio tiempo. $Y$ ese es el saber del espectro: un tiempo irreductible a eso que llamamos "vida" y "muerte", el tiempo de un resto que se obstina, que deja ver, en el vértigo de su espesor, escalas temporales en la que no nos reconocemos, porque son los tiempos de los que está hecho eso que llamamos "cuerpo."

El Informe... hace pivotar la pregunta por el tiempo desde esa materia que no 
es humana, que no se deja reducir a la vida ni a la muerte; es ese tiempo lo que inscribe como desafío a la vez estético y político (2016: 16).

En esa intersección entre lo estético y lo político Giorgi lee la aparición del pueblo y masa como actores políticos. Martín de Mauro ha señalado que la dimensión animal del registro fantasmal en Informe sobre ectoplasma animal cruza y tensa las fronteras entre lo humano y lo animal, entre ciencia y vida, y en un registro historiográfico más amplio, entre ciencia nacional, Estado y violencia (2015: 121). Ese horizonte biopolítico que se comienza a configurar en La comemadre, aquí se manifiesta de manera explícita, ya que en 1930 Solpe contacta a través de cartas al senador Eugenio Dubarry para solicitar apoyo institucional y económico para la Sociedad Ectográfica Argentina.

A partir del uso de la electricidad la ectografía es la ciencia que supone algo parecido a la inmortalidad. El libro incluye una entrada supuestamente transcrita -de ahí las cursivasde Severo Solpe, fechada en 1914 en Buenos Aires, que afirma:

Llamamos espectro a un tipo de residuo matérico inscripto en éter que el animal deja de si cuando muere: la sintesis de sus salivaciones, la huella de los diferentes tamaños de su cuerpo en el tiempo, la silueta, aromas (para su último cumpleaños le regalé a mi esposa el espectro de una mantis en una cajita de cesio con tapa de vidrio, que despide olor a pasto quemado), el diagrama de los movimientos que repitió en circuito, etcétera. Del espectro registramos su ectoplasma, que surge por sustracción eléctrica del cuerpo del ectografista. Sin este auxilio eléctrico, sin este préstamo, el ectoplasma no puede componerse visualmente ante la cámara. En cada ectografía dejamos un poco de nosotros; pagamos las imágenes con una eventual baja de presión, el debilitamiento de las piernas y la contractura momentánea del nervio óptico, que nos hace ver doble (49).

La existencia de los cuerpos de los animales persiste más allá de la muerte, idea que ya estaba presente en La comemadre. En esa novela es la vida humana la que perdura por instantes después de la muerte, mientras que en el Informe, es la muerte de los animales la que persiste en el mundo de los vivos. Según la cita, los animales dejan un residuo material (espectro) que es captado en forma de ectoplasma. Este último funciona como una especie de ensamblaje, ya que es resultado no sólo de la captura de la máquina, sino que de una conjunción en la que participan espectro animal, máquina y la sustracción eléctrica de un cuerpo humano vivo. Según Giorgi, habría "un modo de la memoria, de la persistencia, incluso de la resistencia de la materia de los cuerpos a desaparecer" (2016: s/n). En "Cuerpos inmortales" el crítico de arte y teórico de los medios Boris Groys (2014) afirma de la mano de Foucault y la biopolítica que el estado moderno se define precisamente a partir del derecho de hacer vivir y dejar morir. De un modo coherente con la propuesta de Larraquy en estas dos novelas, Groys rescata doctrinas filosóficas de fines del siglo XIX y principios del XX que proponían la creación de condiciones tecnológicas, sociales y políticas bajo las cuales fuera posible resucitar a toda la gente que alguna vez estuvo viva. Los seguidores de dicha doctrina, los biocosmistas, proponían el arte como 
modelo de la política, y mucho antes que Walter Benjamin, entendían que bajo las condiciones de reproductibilidad técnica no podía haber diferencia entre el "ser humano original" y su copia, de modo que la resurrección era el resultado lógico del proceso de copiado. Para Groys vida y muerte, arte, técnica y política están íntimamente ligados, de un modo cercano a las propuestas escriturales de La comemadre e Informe sobre ectoplasma animal.

En Informe sobre ectoplasma animal la noción de la imagen aparece según Giorgi "no como modulación de la ausencia, sino como canalizador de presencias, de indicios de la presencia”. En ese sentido, la ectografía funcionaría de modo opuesto a la fotografía, es decir, ya no sería una presencia que denota una ausencia - "el haber estado alli" barthesiano-sino todo lo contrario. Según André Bazin "las artes están fundadas en la presencia del hombre; tan sólo en la fotografía gozamos de su ausencia". La fotografía obra sobre nosotros como fenómeno "natural". Para Bazin la fotografía "se beneficia con una transfusión de realidad de la cosa a su reproducción" (1999: 28) y "no crea -como el arte- la eternidad, sino que embalsama el tiempo; se limita a sustraerlo de su propia corrupción" (1999: 29). Los ectoplasmas animales no sólo certificarían la presencia a la vez fantasmática y material del animal, sino que requerirían para materializarse en espectro o visibilizarse, la presencia del hombre como depositario de energía eléctrica. El efecto disruptivo de los ectoplasmas animales, o los espectros en general, es que a diferencia de la fotografía que congela el tiempo, los ectoplasmas animales lo interrumpen y lo dislocan. De hecho su descubrimiento real (ya que su primer anuncio fue apócrifo), sucede en la forma de una interrupción: durante una sesión en el Parque Centenario el viento voltea el trípode con que Solpe trabajaba y al caer al suelo la cámara se dispara. En esa toma involuntaria, aparece la impronta de un pato o ganso espectral (2015: 45).

Si observamos la estructura del texto, vemos que en el Informe los casos descritos están fechados, sin embargo, el archivo que es la novela, no los presenta en orden cronológico, sino que su disposición está trastocada, como si la presencia de estos fantasmas interrumpiera el desarrollo consecutivo de los acontecimientos. Del mismo modo, las imágenes incluidas al interior del libro son una forma desplazada para visibilizar aquello que no podemos ver. Las imágenes interrumpen y acompañan los informes, pero en lugar de un registro realista, fotográfico, como el que se sugiere con el lenguaje científico con el que está escrito el texto, las figuras son geométricas y coloridas", generando un corte con la idea de "documento de lo real" y señalando más bien el lado imaginativo o fabulador de estos espectros.

Hacia el final del libro, la Sociedad Ectográfica Argentina, fundada en 1911, se ha convertido en la década de 1930 en una especie de matadero fantasma, porque los

\footnotetext{
$9 \quad$ Paola Cortés-Rocca ha vinculado el trabajo de Diego Ontivero con la tradición compositiva de las vanguardias de comienzos del siglo XX, sobre todo el suprematismo de Malevich, la influencia de la Bauhaus, o en su versión más argentinas, el arte Madí, movimiento no figurativo, basado en la geometría y el ordenamiento matemático. Cortés-Rocca ha notado cómo a medida que avanza el libro las imágenes "se van despojando de todo ornamento para quedar reducidas a su mínima expresión: el punto y la línea sobre el plano que Kandinsky conceptualiza como el grado cero de la visualidad pictórica. Las ilustraciones del capítulo final, el que transcurre durante el golpe de Uriburu en 1930, retoman los colores originales de la fotografía y operan una fuga de lo figurativo no apostando por desfigurarlo, lo informe o lo abstracto, sino a partir de una matematización del campo visual" (2016a: s/n).
} 
ectoplasmas se generan de manera casi industrial, apoyándose en la idea de que el dolor que sufren los animales asegura la captura de su imagen: "Hábito y dolor son la púa del gramófono que graba en pasta la huella del sonido para su reproducción" (2015: 51). La idea es experimentar hasta el extremo con la captura de la imagen fantasmal de los animales asesinados, sin generar ruido, casi como en la práctica silenciosa y oculta de un campo de concentración. Así comienzan a producirse los llamados "enjambres", que son el ensamblaje de ectoplasmas de hasta seis animales. Estos monstruos espectrales se forman por adición, como el Frankenstein romántico, pero no de restos humanos, sino que de presencias fantasmales de origen animal.

¿Cómo leer estas presencias, estas interrupciones, estas apariciones? Según Giorgi la clave se encuentra en la misma novela: en una carta del 5 de septiembre de 1930 -en la víspera del golpe de Estado de Uriburu-Solpe informa que varios de estos experimentos espectrales se escaparon y terminaron confundiéndose con la muchedumbre que se moviliza ante el golpe de Estado. El resultado: los enjambres se mezclan con la masa informe. La lectura política que hace Giorgi es que la masa "no es nunca exactamente humana", que no está hecha exclusivamente de "sujetos", de identidades culturales o políticas, sino que está conjugada, quizá fundamentalmente, alrededor de potencias entre lo humano y lo nohumano: "La masa está hecha antes que nada de cuerpos, y por lo tanto, por intensidades animales y por intensidades espectrales." Dice Giorgi: "Eso es lo que la imagen revela: que el cuerpo -en su sensorialidad, en su materialidad, pero también en su política- nunca coincide con lo humano; que no hay imagen de lo humano que no pase por el cuerpo, y que ese cuerpo es siempre ya animal" (2016: s/n).

En estas novelas el cuerpo es la materia prima de la experimentación, ya sea de origen científico o artístico. El límite entre estas prácticas parece borrarse, confundiendo estas disciplinas que la modernidad intentó distinguir, separar. En ese sentido, a pesar de estar situadas a inicios del siglo XX estas novelas revelan explícitamente su contemporaneidad. En ellas estos cuerpos en el límite entre la vida y la muerte, se convierten en masa informe, en residuos que es necesario hacer desaparecer, pero que vuelven al presente como espectros ectoplasmáticos o como un archivo material que se imprime sobre los cuerpos, visibilizando aquello que se ha pretendido borrar o silenciar. Es por eso, quizá, que el trabajo con el pasado -y su vínculo con el presente- sea central en estas novelas. Ellas se sitúan desde el presente y proyectan la lectura biopolítica sobre el pasado que ficcionalizan, dando cuenta de jerarquías y de la disponibilidad de los cuerpos para la vida y/o la muerte. El cuerpo, lo material, es lo que persiste e interrumpe el tiempo, siendo capaz de transformarlo, de allí su potencia fantasmal sobre la políticas del presente.

\section{Obras Citadas}

Agamben, Giorgio. 1995. Homo Sacer. El poder soberano y la nuda vida. Valencia: Pre-textos. Bazin, André. 1999. ¿Qué es el cine?. Madrid: Rialp. 
Cortés-Rocca, Paola. 2016a. "Ciencia espectral. Literatura, fotografía y otros dispositivos”. Estudios curatoriales 4. <http://untref.edu.ar/rec/num4_dossier_2.php> . 2016b. "Positivism in Latin America". The Encyclopedia of Postcolonial Studies. Ray, Sangeeta, Henry Schwarz, José Luis Villacañas Berlanga, Alberto Moreiras and April Shemak (eds). Oxford: Blackwell Publishing. <http://www.literatureencyclopedia. $\mathrm{com} />$

De Mauro Rucovsky, Martín. 2015. “Informe sobre ectoplasma humano. Biopolítica y ficción”. Babedec 5 (9): 118-145.

Foucault, Michel. 1998. Historia de la sexualidad. Madrid y México D.F.: Siglo XXI Editores.

Giorgi, Gabriel. 2014. Formas comunes. Animalidad, cultura, biopolitica. Buenos Aires: Eterna Cadencia. . 2015. "Lo real contiene todos sus pasados. Informe sobre espectros". Estudios de Teoría Literaria. Revista digital: Artes, letras y humanidades. 4 (8): 13-22. . 2016. "El animal, el espectro". La Fuga 17. Consultado el 20 de diciembre 2016. <http://2016.lafuga.cl/el-animal-el-espectro/747>

Groys, Boris. 2014. Volverse público. Trad. Paola Cortés-Rocca. Buenos Aires: Caja Negra Editora.

Larraquy, Roque. 2010. La comemadre. Buenos Aires: Editorial Entropía.

Larraquy, Roque y Diego Ontivero. 2014. Informe sobre ectoplasma animal. Buenos Aires: Eterna Cadencia.

Marún, Gioconda. 1995, "Darwin y la literatura argentina del siglo XIX." Actas del XII Congreso de la Asociación de Hispanistas: 21-26 de agosto de 1995. Dept. of Hispanic Studies, The University of Birmingham: 82-91.

Piglia, Ricardo. 2000. Critica y ficción. Buenos Aires: Planeta (Seix Barral).

Quereilhac, Soledad. 2016. Cuando la ciencia despertada fantasías. Prensa, literatura y ocultismo en la Argentina de entresiglos. Buenos Aires: Siglo XXI Editores.

Sarlo, Beatriz. 1997. La imaginación técnica. Buenos Aires: Ediciones Nueva Visión. 
